\title{
AGRESIVITAS AIRTANAH KARST SUNGAI BAWAH TANAH BRIBIN, GUNUNG SEWU
}

\author{
Oleh : Tjahyo Nugroho Adji \\ Laboratorium Geohidrologi-Fakultas Geografi UGM \\ Email: adji@geo.ugm.ac.id
}

\begin{abstract}
Karst groundwater agressivity, which is here meant as the ability of water to dissolve limestone plays a significant role to sustain the discharge of Bribin River. This article describes the spatial karst groundwater agressivity of Bribin underground river along flowpath. The boundary of analysis used in this research is the tentative catchment area of Bribin River starting from Pentung River (swallow hole) as an inlet and Bribin Cave as the end point (outlet).

39 caves within the catchment were mapped, and 8 underground river were sampled and analyzed in laboratory to achieve the chemical composition of groundwater including cation $\left(\mathrm{Ca}^{2+}, \mathrm{Mg}^{2+}, \mathrm{Na}^{+}, \mathrm{K}^{+}\right)$and anion $\left(\mathrm{Cl}^{-}, \mathrm{SO}_{4}{ }^{2-}, \mathrm{HCO}_{3}{ }^{-}\right)$. Afterwards, the result of laboratory is used to identify the chemical type of karst groundwater. Groundwater agressivity is subsequently classified by using chemical agressivity diagram in the system of $\mathrm{pH}-\mathrm{T}^{\circ} \mathrm{C}-\mathrm{CaCO}_{3}$ in order to account the $\Delta \mathrm{pH}$ and $\triangle \mathrm{TAC}$. Finally, using the value of $\Delta \mathrm{pH}$ and $\triangle T A C$, the rate of karst groundwater agressivity may be defined. In addition, to define the stage of dissolution process along flowpath, analysis of Saturation Indices $(\mathrm{SI})$ with respect to calcite $\left(\mathrm{CaCO}_{3}\right)$ is also to be applied.

The result indicates that there is a tendency of the decreasing rate of groundwater agressivity along flowpath. The inlet (Pentung River) characterized by high groundwater agressivity, and then there is a moderate decreasing trend of groundwater agressivity downstream. Finally, the rate of agressivity in the end point (Bribin Cave) confirms the low agressivity stage occurs. Furthermore, the analysis of SI values shows that the dominant hydrogeochemical processes is calcite dissolution, even though this values is very close to equilibrium at Bribin Cave. Meanwhile, interesting phenomena present in Sodong Cave, where the sample is classified as aggressive water with the SI value of -0.43 inevitable that leakage of Bribin River may occur in the future.
\end{abstract}

Keywords : karst groundwater, agressivity, saturation indices

\section{PENDAHULUAN}

Kondisi hidrologi di daerah karst dapat dikatakan unik dan mempunyai karakteristik yang sangat berbeda dibandingkan dengan kondisi airtanah di kawasan lain. Keunikan ini lebih disebabkan karena proses pembentukan geomorfologi bawah permukaan karst yang didominasi oleh proses pelarutan (solusional). Hal ini mengakibatkan minimnya aliran permukaan dan lebih berkembangnya sistem aliran bawah permukaan berupa lorong-lorong dan sungai bawah tanah. Lorong-lorong dan sungai bawah tanah ini secara hidrogeologis dikenal sebagai porositas sekunder, sementara oleh Gillieson (1996) disebut porositas lorong, yang terjadi karena proses pelarutan (dissolution) pada batuan karbonat.

Sungai bawah tanah Bribin merupakan salah satu sungai utama di kawasan karst Gunung Sewu dengan debit yang cukup besar. Pada musim kemarau debit terukur adalah sekitar 800 liter/detik, sementara pada musim penghujan dapat mencapai 1500 liter/detik (Mc Donald and Partners (1984). Penelitian Fakultas Kehutanan (1993) menyebutkan bahwa dari total debit yang dijumpai pada Sungai Bribin, baru sekitar 120 liter/detik yang sudah dimanfatkan dan didistribusikan untuk memenuhi kebutuhan domestik penduduk sekitar. Akhir-akhir ini, kerjasama antara Pemerintah Provinsi (Pemprov) Daerah Istimewa Yogyakarta (DIY) dengan Universitas Kalsruhe Jerman dan Batan sudah memulai pemboran dan membuat bendung bawah tanah dengan ketinggian 6 meter dan luas 15 meter $^{2}$ yang diharapkan dapat menghasilkan listrik sebesar $250 \mathrm{~s} / \mathrm{d} 300 \mathrm{KW}$ yang akan digunakan untuk meningkatkan kapasitas layanan distribusi airtanah karst ini menjadi dua kali lipat dari sebelumnya (Sinar Harapan, 2004).

Melihat uraian diatas, tampak bahwa harapan terhadap kelangsungan sumberdaya airtanah Sungai Bribin sangat besar dan juga mengingat besarnya investasi yang mencapai 2 trilyun rupiah (Suara Merdeka, 2004). Sementara itu jika kita melihat kenyataan bahwa proses karstifikasi dan pelarutan batuan 
gamping yang menjadi ciri khas daerah karst, maka dapat dikatakan bahwa proses pembentukan lorong masih berlangsung di sungai bawah tanah Bribin. Lebih jauh lagi dapat ditengarai pula bahwa loronglorong solusional masih mungkin terbentuk di sepanjang Sungai Bribin yang tentu saja akan dapat mengganggu stabilitas kelangsungan debit air di Sungai Bribin. Identifikasi awal menyebutkan bahwa pada upstream Goa Bribin terdapat lorong goa yang mempunyai aliran menuju Goa Sodong yang diamati mempunyai debit yang semakin membesar dari tahun ke tahun. Pengukuran pada tahun 2003 (tidak dipublikasikan) sudah mendekati angka 25 liter/detik, sementara hasil pengukuran oleh Adji (1997) debit Goa Sodong masih sekitar 15 liter/detik. Kenyataan ini dapat memberikan gambaran bahwa terjadi kebocoran sekitar 10 liter/detik pada kisaran waktu selama 6 tahun pada satu titik saja, sementara sangat sulit untuk mengidentifikasi kebocoran pada titik-titik lain sepanjang sungai utama Bribin yang sudah dipetakan.

Artikel ini akan membahas bagaimana sebaran spasial dari sifat agresivitas airtanah karst di sepanjang sungai bawah tanah Bribin dari hulu sampai hilir pada satu kali periode pengukuran dan pengambilan sampel. Manfaat dari tulisan ini adalah agar dapat diketahui secara kuantitatif dan spasial lokasi-lokasi dengan kemampuan airtanah karst untuk melarutkan batuan karbonat maupun yang sudah tidak berpotensi lagi untuk melarutkan batuan karbonat (agresivitas rendah).

\section{PELARUTAN BATUAN KARBONAT}

Komposisi kimia airtanah pada suatu wilayah sangat tergantung dari interaksi antara airtanah dan mineral penyusun batuan dengan proses utama berupa pelarutan (dissolution). Menurut Appelo and Postma (1993), terdapat tiga fase yang berkatian dengan proses ini yaitu (1) kondisi air tidak jenuh (undersaturated), sehingga masih mampu untuk melarutkan mineral batuan (2) kondisi seimbang (equilibrium), proses pelarutan sudah berhenti, dan (3) kondisi air sudah jenuh (supersaturated) terjadi proses pengendapan (precipitation). Selanjutnya, Jankowski (2001) mengungkapkan bahwa ada dua syarat utama suatu formasi karst dapat terbentuk karena proses pelarutan oleh air yaitu sifat air yang melalui karst haruslah tidak jenuh (undersaturated) terhadap batuan karbonat, dan air tersebut haruslah mampu men-transport pruduk hasil pelarutan ke tempat lain. Kondisi air yang cocok untuk pelarutan batuan karbonat ini adalah air freatik dan juga air hujan (meteoric water) yang kaya akan $\mathrm{CO}_{2}$. Air ini biasa masuk ke formasi karbonat secara gravitasi dan kemudian mampu membentuk lorong-lorong solusional. Lebih jauh lagi Jankowski menjelaskan bahwa untuk memperoleh air yang bersifat tidak jenuh terhadap batuan karbonat ada beberapa mekanisme yang sering terjadi pada airtanah karst yaitu perubahan suhu, percampuran (mixing) dengan air yang mempunyai sifat lain, terjadinya banjr di permukaan yang menyebabkan imbuhan yang cepat dan bersifat tidak jenuh, dan meningkatnya kondisi keasaman air sepanjang aliran airtanah.

Secara ringkas, Bogli (1980) menjelaskan bahwa pada proses pelarutan batuan karbonat oleh air hujan dari udara dan jatuh ke permukaan terjadi banyak proses fisik dan kimia yang melibatkan unsur gas, cair dan padatan yang menyebabkan perpindahan massa antara udara, air, dan batuan seperti yang diilustrasikan pada Gambar 1.

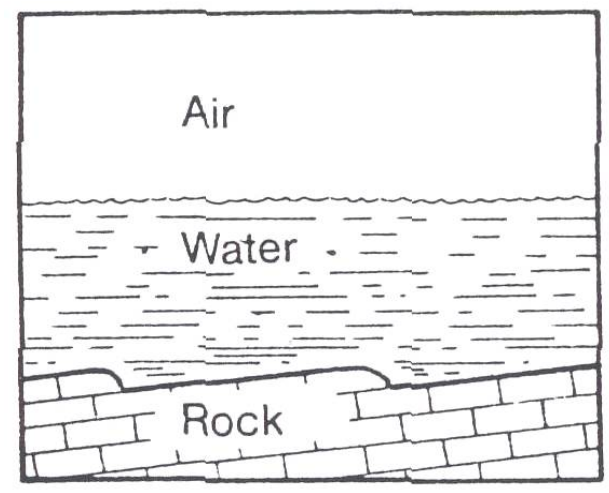

Gambar 1. Perpindahan massa melalui interface udara/air dan udara/batuan (Bogli, 1980) 


\section{Citation: Gunung Sewu-Indonesian Cave and Karst J ournal, Vol 1 No.1,April 2003}

Pada umumnya, proses yang terjadi di interface/batas adalah transfer massa adn difusi, sementara proses kimia lebih dominan terjadi di air. Jika kita melihat Gambar 1, dapat disimpulkan bahwa sistem perpindahan massa yang terjadi adalah sistem karbonat yang dikenal sebagai sistem $\mathrm{CO}_{2}-\mathrm{H}_{2} \mathrm{O}^{-}$ $\mathrm{CaCO}_{3}$, yang menurut Bogli mempunyai tahapan proses sebagai berikut :

(1) ketika terjadi hujan, gas karbondioksida $\left(\mathrm{CO}_{2}\right)$ di atmosfer masuk ke dalam air melalui proses difusi

(2) kemudian, air yang mengandung $\mathrm{CO}_{2}$ bersenyawa membentuk asam karbonat (carbonic acid) dengan reaksi kimia $\mathrm{CO}_{2}$ (di air) $+\mathrm{H} 2 \mathrm{O}$---------- $\mathrm{H}_{2} \mathrm{CO}_{3}$, dan dapat dikatakan bahwa gas karbondioksida larut dalam air

(3) karena $\mathrm{H}_{2} \mathrm{CO}_{3}$ merupakan asam kuat, maka dapat mengalami dissociation (perpecahan) yaitu yang pertama $\mathrm{H}_{2} \mathrm{CO}_{3}$-------- $\mathrm{HCO}_{3}^{-}+\mathrm{H}^{+}$dan yang kedua adalah $\mathrm{HCO}_{3}^{-}$ dengan proporsi yang kecil dibawah $\mathrm{pH} 8,4$ sehingga dapat diabaikan.

Untuk ilustrasi, tahapan 1 sampai 3 disajikan pada Gambar 2.

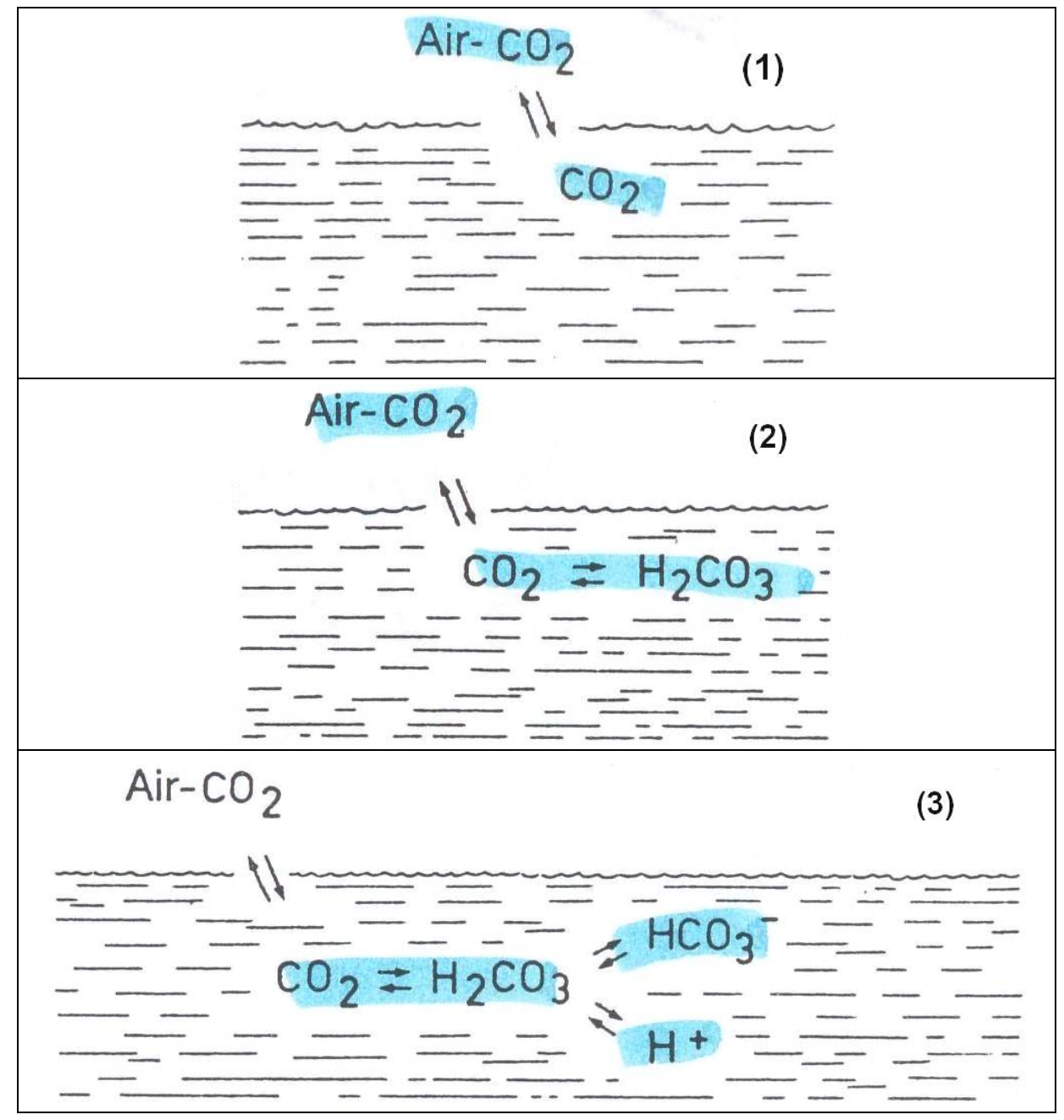

Gambar 2. Proses 1-3 pelarutan batuan karbonat (Bogli, 1980)

Seementara itu proses selanjutnya adalah :

(4) ketika air dan batuan karbonat berinteraksi, terjadi pelepasan ion dan kemudian terjadi reaksi pelarutan karbonat $\mathrm{CaCO}_{3}$ $\mathrm{Ca}^{2+}+\mathrm{CO}_{3}^{-}$ 
(5) selanjutnya, $\mathrm{CO}_{3}{ }^{-}$bergabung dengan ion $\mathrm{H}^{+}$yang lepas pada reaksi (3) sehingga $\mathrm{CO}_{3}{ }^{2-}+\mathrm{H}^{+}$ $\mathrm{HCO}_{3}^{-}$

Untuk ilustrasi, proses (4) dan (5) disajikan pada Gambar 3.

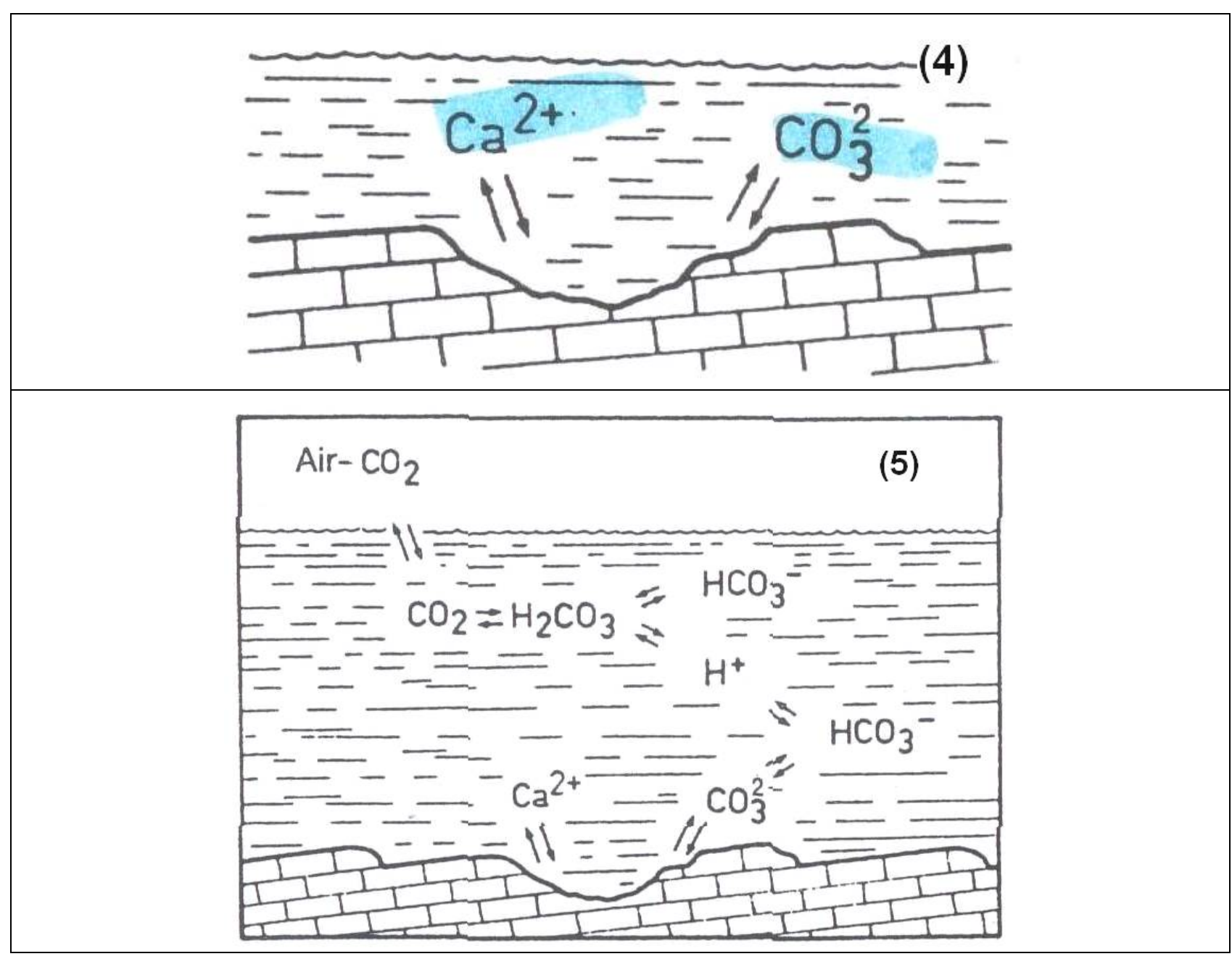

Gambar 3. Proses pelarutan karbonat (4) yang diiukutioleh pembentukan bikarbonat (5) (Bogli, 1980)

Dari proses diatas terlihat bahwa semakin air itu banyak mengandung karbondioksida, maka semakin mudah pula air itu untuk melarutkan batuan karbonat. Dengan kata lain, jika suatu sampel air banyak mengandung $\mathrm{Ca}^{2+}$ dan $\mathrm{HCO}_{3}{ }^{-}$, maka air itu dapat dikatakan semakin tidak agresiv pada kondisi termodinamika ( $\mathrm{pH}$;suhu) yang sama. Akan halnya di sungai bawah tanah Bribin, penelitian tentang sebaran nilai agresivitas airtanah karst belum tersedia termasuk bagaimana kondisi termodinamikanya yang didekati dengan nilai $\mathrm{pH}$ dan suhu. Jika pertanyaan diperluas lagi, bagaimana kondisi dan tipe aliran yang dominan di sungai bawah tanah Bribin, apakah bertipe conduit atau fissure/diffuse atau bahkan campuran diantara keduanya, dan bagaimana pula sifat agresivitasnya untuk membentuk lorong conduit secara spasial bahkan mungkin secara temporal?.

\section{KONDISI SUNGAI BAWAH TANAH BRIBIN}

Kondisi dan sebaran goa pada sungai bawah tanah yang dibahas pada artikel ini mengunakan pendekatan ruang lingkup berupa daerah tangkapan hujan tentatif yang dibuat oleh Fakultas Kehutanan (1993). Batas daerah tangkapan hujan ini menggunakan topografi permukaan sebagai acuan penentuan batas wilayah. Beberapa penelitian sesudahnya yaitu Adji (1997), Adji dan Emilya (1999) serta Setyahadi (2002) menggunakan batas ini sebagai batas daerah penelitian, walupun disadari bahwa batas ini bisa 
saja salah karena belum ada pembuktian yang sifatnya empiris maupun eksperimental mengingat sistem lorong-lorong karst yang sulit dijangkau.

Batas daerah tangkapan hujan tentatif Sungai Bribin ini meliputi 3 kecamatan di Kabupaten Gunung Kidul yaitu Kecamatan Ponjong, Semanu, dan Rongkop. Secara astronomis berdasarkan peta topografi lembar Jawa skala 1:50.000 edisi 1-AMS (FE) terletak antara $7056^{\circ}$ - $805^{`}$ LS dan 1100 40 $110048^{`}$ BT. Melihat batas-batas diatas luas total wilayah ini mencakup kurang lebih 55,77 km².

Selanjutnya, terdapat 39 goa yang terdistribusi di daerah tangkapan sungai bawah tanah Bribin ini. Sebagian besar goa yang ada bertipe horisontal dan beberapa vertikal dengan kedalaman ada yang mencapai 150 meter (Luweng Bodeh). Dari 39 goa yang tercakup pada daerah Tangkapan Bribin ini, hanya terdapat 12 goa atau luweng yang didominasi oleh lorong-lorong bertipe vadose dan tidak berair. Sementara 23 buah goa dan luweng diantaranya mempunyai aliran bawah tanah (beberapa mempunyai debit cukup besar).

Sementara itu, dari penelitian terdahulu oleh McDonald and Partners (1984) dan Fakultas Kehutanan (1993) terungkap bahwa hulu Sungai Bribin bermula dari Sungai Pentung yang masul ke ponor di daerah Sawah Ombo, Tambakromo, yang kemudian ditemui lagi di Goa Jomblangan, kemudian di Goa Gilap, Goa Jomblang, Luweng Jurang jero, dan terakhir di Goa Bribin. Lebih jauh lagi Adji (1997) mendeskripsikan Sungai Bribin itu sebagai suatu sistem pergoaan yang terbagai atas (1) aliran primer yang merupakan aliran utama Sungai Bribin yang telah dibuktikan sebagai sungai utama dan (2) aliran sekunder yang merupakan sub aliran atau cabang dari sungai utama baik itu yang keluar ataupun yang masuk ke/dari sungai utama. Sebagai contoh adalah Goa Sodong (keluar) dan Luweng Ombo 1 (masuk). Untuk lebih jelasnya, cakupan daerah tangkapan hujan serta sebaran goa dan sistem aliran Sungai Bribin disajikan pada Gambar 4.

\section{METODOLOGI}

Pada penelitian ini, tidak semua goa yang dialiri air diambil sampelnya tetapi dipilih goa-goa yang berada pada aliran primer Sungai Bribin. Seperti yang disajikan pada Gambar 4, 8 lokasi goa maupun sungai bawah tanah diambil sampel kualitas airnya. Pengambilan sampel ini didasarkan pada sebaran penggal Sungai Bribin yang dimulai dari hulu (daerah Tambak Romo) dan berakhir di Goa Bribin (Dadapayu). Tabel 1. berikut ini menyajikan posisi geografis sampel dan kondisi hidrologisnya. 


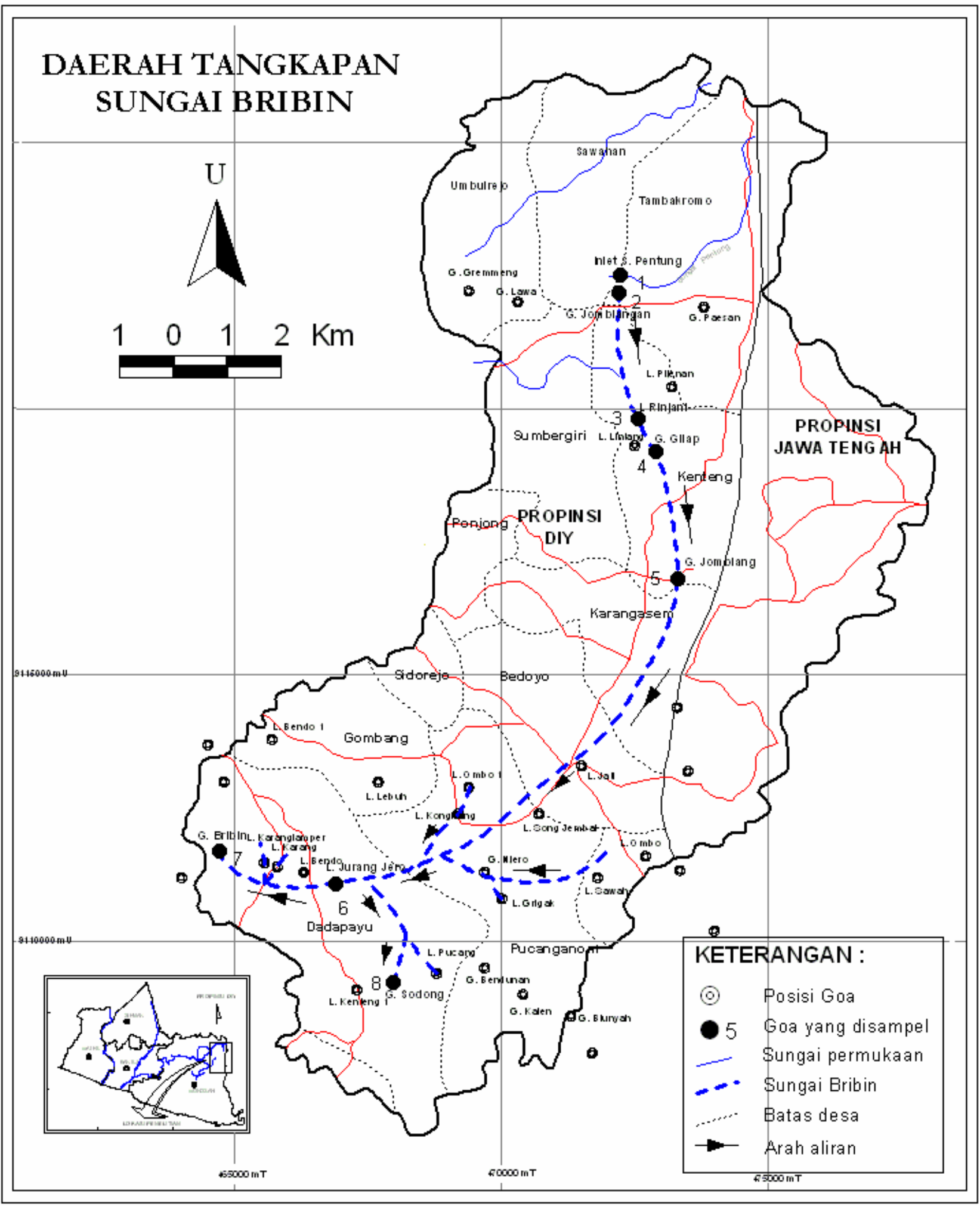

Gambar 4. Daerah Tangkapan Sungai Bribin dan Posisi Goa yang Disampel 
Tabel 1. Posisi dan kondisi hidrologis lokasi sampel Sungai Bribin

\begin{tabular}{|c|l|c|c|c|c|}
\hline $\begin{array}{c}\text { No } \\
\text { sampel }\end{array}$ & \multicolumn{1}{|c|}{ Nama Goa } & $\begin{array}{c}\text { Kedalaman } \\
(\mathrm{m})\end{array}$ & Koordinat & $\begin{array}{c}\text { Debit } \\
(\mathrm{lt} / \mathrm{dt})\end{array}$ & Aliran \\
\hline 1 & Inlet S. Pentung & - & $472152 ; 9122480$ & 10 & sungai permukaan \\
\hline 2 & G. Jomblangan & +25 & $472212 ; 9122178$ & 37 & primer \\
\hline 3 & G. Rinjani & +174 & $472563 ; 9119769$ & 4 & sub-primer \\
\hline 4 & G. Gilap & +71 & $472890 ; 9119224$ & 30 & primer \\
\hline 5 & G. Jomblang & +134 & $473289 ; 9116815$ & 350 & primer \\
\hline 6 & L. Jurang Jero & -64 & $466886 ; 9111126$ & 1500 & primer \\
\hline 7 & G. Bribin & +33 & $464695 ; 9111695$ & 1200 & primer \\
\hline 8 & G. Sodong & +41 & $467983 ; 9109165$ & 15 & outlet-bocor \\
\hline
\end{tabular}

Sumber : Fakultas Kehutanan (1993) dan Adji (1997)

Setelah sampel diambil, dilakukan pengukuran dan analisis di laboratorium terhadap unsur mayor terlarut berupa kation $\left(\mathrm{Ca}^{2+}, \mathrm{Mg}^{2+}, \mathrm{Na}^{+}, \mathrm{K}^{+}\right)$dan anion $\left(\mathrm{Cl}^{-}, \mathrm{SO}_{4}{ }^{2-}, \mathrm{HCO}_{3}{ }^{-}\right)$Cara analisis laboratorium yang digunakan meliputi : metode volumetri untuk unsur $\mathrm{Ca}^{2+}, \mathrm{Mg}^{2+}, \mathrm{CO}_{3}{ }^{-}$dan $\mathrm{SO}_{4}{ }^{2-}$; metode spektrofotometri untuk unsur $\mathrm{HCO}_{3}^{-}$; metode flamefotometri untuk unsur $\mathrm{Na}^{+}$dan $\mathrm{K}^{+}$.

Analisis terhadap index kejenuhan atau Saturation Indices (SI) terhadap mineral penyusun akuifer adalah salah satu cara yang dapat digunakan untuk mengetahui sampai sejauh mana air itu bereaksi dengan batuan, apakah masih dalam fase tidak jenuh (unsaturated) sehingga masih ada reaksi pelarutan (dissolution) ataukah dalam kondisi seimbang (equilibrium) ataukah airtanah tersebut sudah ada pada fase jenuh (super saturated) sehingga terjadi proses pengendapan (precipitation) menghasilkan padatan. Dengan indeks ini dapat diketahui apakah proses reaksi masih berlangsung atau sudah berhenti, seperti yang disajikan pada Tabel 2.

Tabel 2. Fase Pelarutan atau Pengendapan terhadap Mineral Karbonat $\left(\mathrm{CaCO}_{3}\right)$

\begin{tabular}{|l|l|l|}
\hline \multicolumn{1}{|c|}{ Nilai SI } & \multicolumn{1}{c|}{ Klasifikasi } & \multicolumn{1}{c|}{ Proses Hidrogeokimia } \\
\hline Negatif $(<0)$ & Tidak jenuh (undersaturated) & Masih mampu melarutkan kalsit \\
\hline 0 & Seimbang (equilibrium) & Seimbang \\
\hline Positif $(>0)$ & Jenuh (supersaturated) & Mengkristal /membentuk padatan (solid) \\
\hline
\end{tabular}

Ford and Williams(1992)

Analisis Indeks kejenuhan disini tentu saja dilakukan hanya terhadap mineral kalsit $\left(\mathrm{CaCO}_{3}\right)$ yang dominan terdapat pada batuan di daerah penelitian. Analisis ini dilakukan dengan bantuan software NETPATH 2.1.3 (Plummer et.al, 1991), dan setelah nilai diperoleh dilakukan analisis grafikal dari hulu ke hilir searah Sungai Bribin dan menganalisisnya secara spasial dengan cara memplot nilai tersebut kedalam peta.

Agresivitas airtanah karst merurut Ford and Williams (1992) terpengaruh ole faktor-faktor termodinamika yaitu kandungan derajat keasaman dan suhu yang menyebabkan perbedaan kandungan $\mathrm{CaCO}_{3}$ terlarut dalam air. Selanjutnya, metode yang digunakan untuk mengetahui agresivitas airtanah karst adalah menggunakan diagram agresivitas kimia pada sistem $\mathrm{pH}-\mathrm{T}^{\circ} \mathrm{C}-\mathrm{CaCO}_{3}$ (derajat keasamansuhu-kesadahan) yang dikembangkan oleh Jankowski (2001) untuk menghitung selisih $\mathrm{pH}(\Delta \mathrm{pH})$ dan selisih TAC ( $\triangle T A C)$ tiap sampel airtanah karst yang diteliti. TAC adalah nilai yang dimunculkan untuk mewakili kandungan $\mathrm{CaCO}_{3}$ terlarut dengan asumsi bahwa $1 \mathrm{TAC}=10 \mathrm{mg} / \mathrm{lt} \mathrm{CaCO}_{3}$. Untuk ilustrasi metode yang digunakan disajikan pada Gambar 5. 
Citation: Gunung Sewu-Indonesian Cave and Karst J ournal, Vol 1 No.1,April 2003

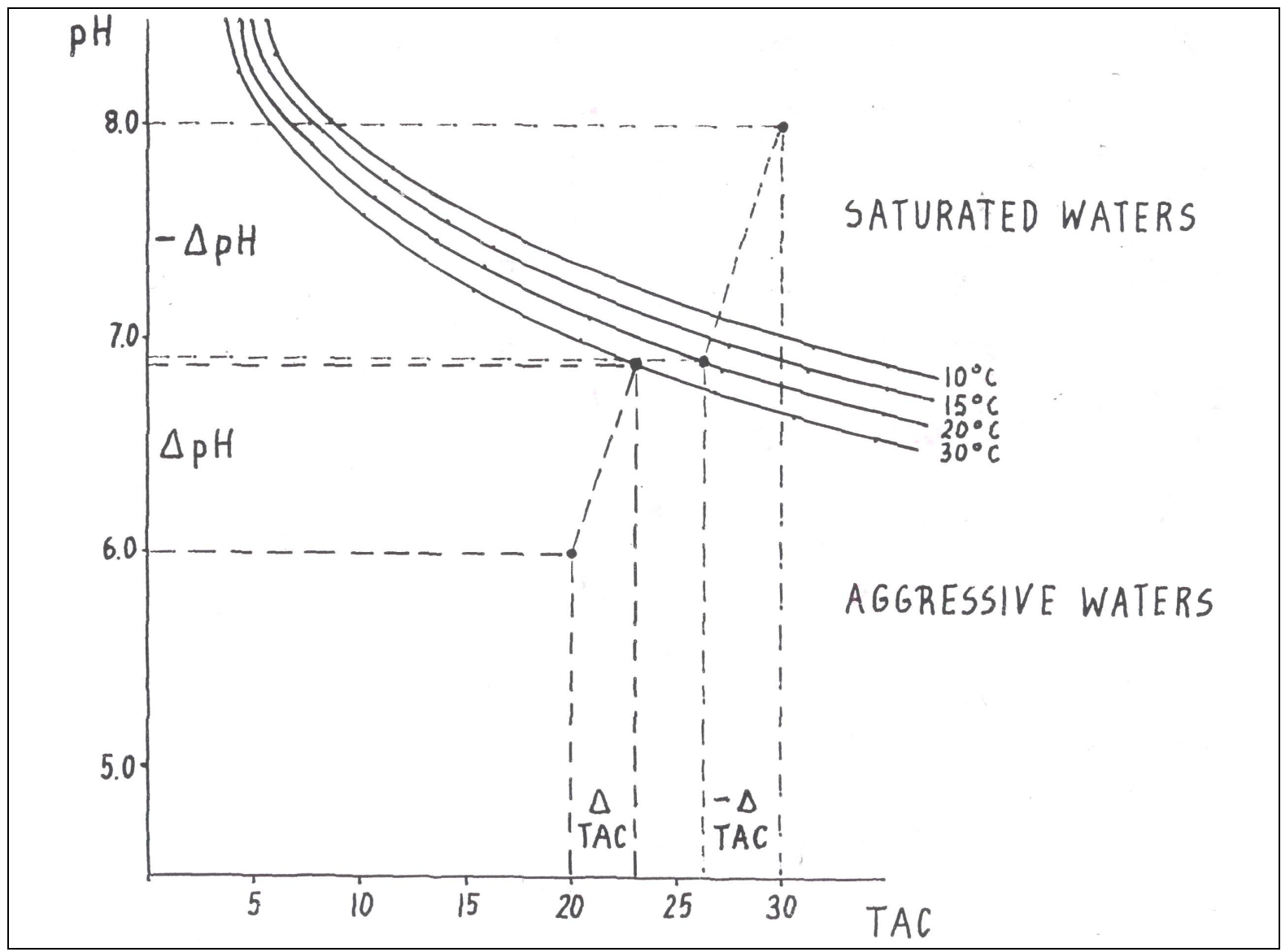

Gambar 5. Agresivitas Kimia Airtanah Karst pada sistem pH-suhu-CaCO3 dan metode untuk menghitung $\Delta \mathrm{pH}$ dan $\triangle \mathrm{TAC}$ (Jankowski, 2001)

Setelah $\triangle \mathrm{pH}$ dan $\triangle \mathrm{TAC}$ diperoleh, pengkelasan dapat dilakukan dengan menggunakan grafik hubungan antara $\triangle \mathrm{pH}$ dan $\triangle T A C$ dengan pengkelasan oleh Jankowski (2001) sebagai berikut dan ditunjukkan pula pada Gambar 6 :
a) Kelas $1:$ saturated water (air jenuh)
b) Kelas 2 : moderately saturated water (air agak jenuh)
c) Kelas 3 : slightly saturated water (air sedikit jenuh)
d) Kelas 4 : equilibriated water (air setimbang)
e) Kelas 5 : slightly aggressive water (air sedikit agresiv)
f) Kelas 6 : moderately agresive water (air agak agresiv)
g) Kelas 7 : aggressive water (air agresiv) 


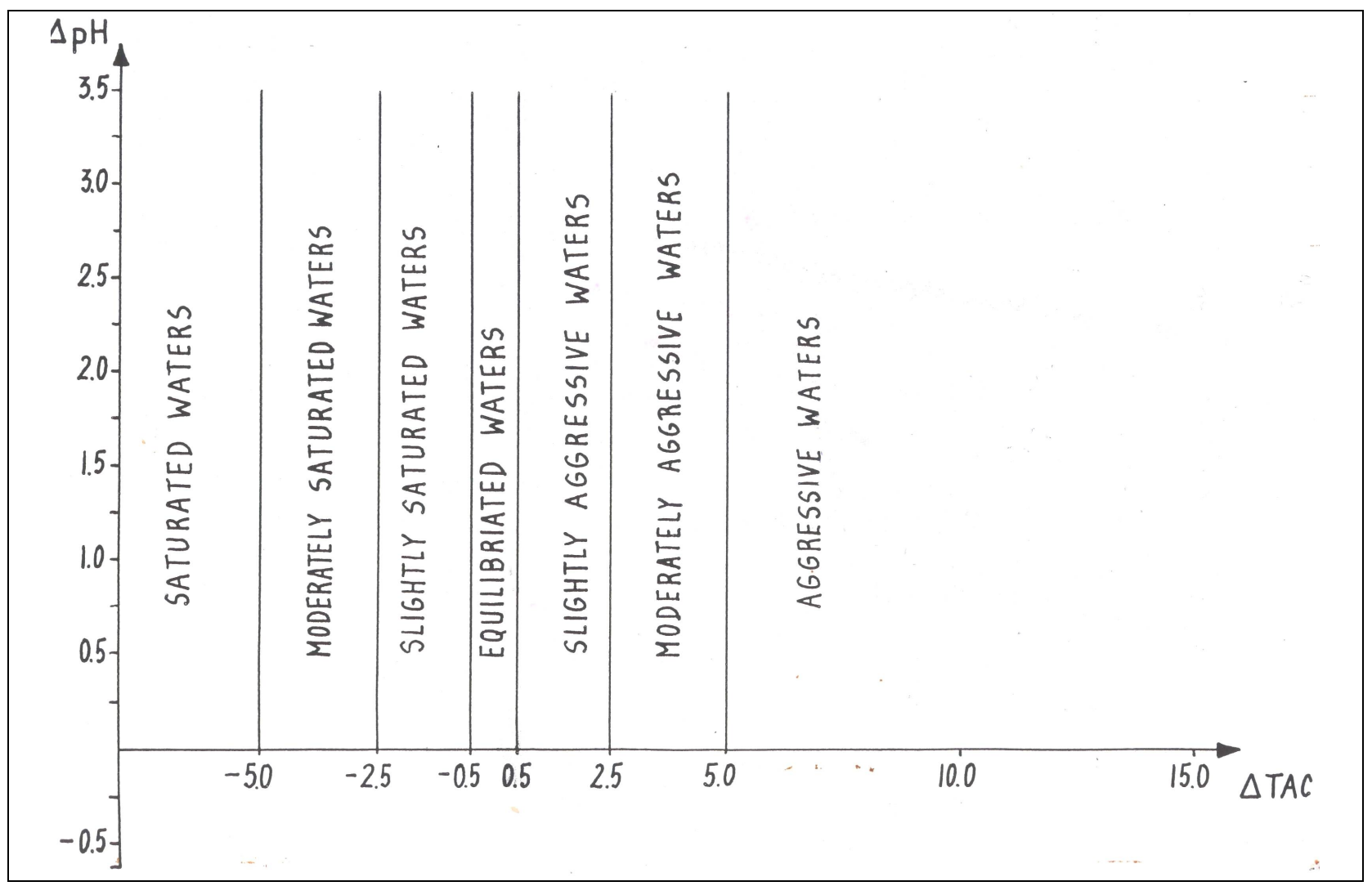

Gambar 6. Derajat Agresivitas Airtanah Karst Atas Dasar $\Delta \mathrm{pH}$ dan $\triangle \mathrm{TAC}$ (Jankowski, 2001)

\section{HASIL DAN PEMBAHASAN}

\section{Komposisi kimia sampel airtanah karst}

Setelah dilakukan analisis laboratorium terhadap unsur kation dan anion, komposisi kimia airtanah karst disajikan pada Tabel 3.

Tabel 3. Hasil Analisis Laboratorium Kualitas Air Sampel Sungai Bribin Dari Hulu-Hilir (dalam mg/liter)

\begin{tabular}{|r|l|l|l|l|l|l|l|l|l|l|l|}
\hline No & \multicolumn{1}{|c|}{ Sampel } & $\begin{array}{c}\text { Suhu } \\
(\mathrm{oC})\end{array}$ & $\mathrm{pH}$ & $\mathrm{Ca}^{2+}$ & $\mathrm{Mg}^{2+}$ & $\mathrm{Na}^{+}$ & $\mathrm{K}^{+}$ & $\mathrm{HCO}_{3}^{-}$ & $\mathrm{SO}^{2-}$ & $\mathrm{Cl}^{-}$ & \multicolumn{1}{|c|}{ Tipe Kimia } \\
\hline 1 & Inlet S Pentung & 26.67 & 6.32 & 30.1 & 3.40 & 6.50 & 3.40 & 176.00 & 4.30 & 2.30 & $\mathrm{HCO}_{3}-\mathrm{Ca}$ \\
\hline 2 & G. Jomblangan & 26.89 & 6.67 & 47.30 & 5.77 & 3.80 & 2.40 & 227.00 & 3.00 & 5.82 & $\mathrm{HCO}_{3}-\mathrm{Ca}$ \\
\hline 3 & G. Rinjani & 27.01 & 6.78 & 60.60 & 5.47 & 1.20 & 1.00 & 103.00 & 1.80 & 5.17 & $\mathrm{HCO}_{3}-\mathrm{Ca}$ \\
\hline 4 & G. Gilap & 27.22 & 6.88 & 57.30 & 11.50 & 5.40 & 2.20 & 264.00 & 9.30 & 3.88 & $\mathrm{HCO}_{3}-\mathrm{Ca}$ \\
\hline 5 & G. Jomblang & 27.09 & 6.77 & 89.50 & 21.00 & 0.80 & 0.30 & 245.00 & 1.60 & 5.82 & $\mathrm{HCO}_{3}-\mathrm{Ca}$ \\
\hline 6 & L. Jurangjero & 27.29 & 6.92 & 97.10 & 12.30 & 0.90 & 0.30 & 253.00 & 4.70 & 5.82 & $\mathrm{HCO}_{3}-\mathrm{Ca}$ \\
\hline 7 & G. Bribin & 27.25 & 6.99 & 134.40 & 9.18 & 58.20 & 2.50 & 238.00 & 14.00 & 7.76 & $\mathrm{HCO}_{3}-\mathrm{Ca}$ \\
\hline 8 & G. Sodong & 27.12 & 6.88 & 77.30 & 10.01 & 8.40 & 1.40 & 161.00 & 11.00 & 5.52 & $\mathrm{HCO}_{3}-\mathrm{Ca}$ \\
\hline
\end{tabular}

Secara umum komposisi kimia sampel yang diambil merupakan tipe dari airtanah karst dan dibuktikan pula oleh tipe kimia airtanah yang dianalisis dengan menggunakan klasifikasi menurut Szczukariew-Priklonski (Alekin, 1970). Tipe kimia menurut klasifikasi ini mendasarkan pada prosentase masing-masing anion dan kation yang mempunyai komposisi lebih dari $20 \%$ dalam satuan meq/l. Selanjutnya, semua sampel mempunyai tipe kimia $\mathrm{HCO}_{3}$-Ca yang kemudian dapat disimpulkan bahwa ion yang dominan terlarut adalah kalsium dan bikarbonat sesuai dengan tipikal airtanah karst yang bermineral dominan kalsit. Selain itu, tipe kimia pada sungai permukaan inlet Sungai Pentung juga mempunyai tipe 
yang sama yang mengindikasikan bahwa komponen aliran permukaan masih didominasi oleh rembesan dari kawasan pinggiran karst.

Selanjutnya, hasil plotting dan analisis menggunakan grafik seperti yang sudah dijelaskan pada Gambar 5 dan 6 memberikan hasil analisis seperti yang disajikan pada Tabel 4.

Tabel 4. Sifat Agresivitas Airtanah Karst Sungai Bribin

\begin{tabular}{|r|l|c|r|r|r|r|c|}
\hline No & \multicolumn{1}{|c|}{ Sampel } & \multicolumn{1}{|c|}{$\begin{array}{c}\text { Koordinat } \\
\left({ }^{\circ} \mathrm{C}\right)\end{array}$} & \multicolumn{1}{c|}{$\mathrm{pH}$} & \multicolumn{1}{c|}{$\begin{array}{c}\mathrm{Ca}^{2+} \\
(\mathrm{mg} / \mathrm{t})\end{array}$} & \multicolumn{1}{|c|}{ TAC } & Derajat Agresivitas \\
\hline 1 & Inlet S Pentung & $472152 ; 9122480$ & 26,67 & 6,32 & 30,1 & 7,5 & Air agresiv \\
\hline 2 & G. Jomblangan & $472212 ; 9122178$ & 26,89 & 6,67 & 47,30 & 11,82 & Air agak agresiv \\
\hline 3 & G. Rinjani & $472563 ; 9119769$ & 27,01 & 6,78 & 60,60 & 15,15 & Air agak agresiv \\
\hline 4 & G. Gilap & $472890 ; 9119224$ & 27,22 & 6,88 & 57,30 & 14,32 & Air sedikit agresiv \\
\hline 5 & G. Jomblang & $473289 ; 9116815$ & 27,09 & 6,77 & 89,50 & 22,4 & Air sedikit agresiv \\
\hline 6 & L. Jurangjero & $466886 ; 9111126$ & 27,29 & 6,92 & 97,10 & 24,3 & Air setimbang \\
\hline 7 & G. Bribin & $464695 ; 9111695$ & 27,25 & 6,99 & 134,40 & 33,6 & Air setimbang \\
\hline 8 & G. Sodong & $467983 ; 9109165$ & 27,12 & 6,88 & 77,30 & 19,33 & Air agak agresiv \\
\hline
\end{tabular}

Secara umum, kondisi airtanah karst di Sungai Bribin dari hulu ke hilir masih mempunyai sifat agresivitas untuk melarutkan batuan karbonat. Secara spasial, agresivitas makin menurun kearah hulu, kecuali ditemukan kenaikan tingkat agresivitas pada bocoran upsteam Goa Bribin kearah Goa Sodong. Beberapa hal yang dapat disampaikan disini adalah bahwa masuknya sungai permukaan yang tentu saja bersifat tidak jenuh terhadap mineral kalsit berpengaruh terhadap distribusi nilai agresivitas airtanah karst untuk melarutkan batuan karbonat. Penelitian lebih lanjut mutlak dilakukan untuk menelusuri bocoran upstream Goa Bribin kearah Goa Sodong mengingat asal air di Goa Bribin yang sudah bersifat seimbang (equilibrium) menjadi bersifat agak agresiv ketika keluar di Goa Sodong. Prediksi sementara yang dapat menjelaskan hal ini adalah adanya percampuran (mixing) dengan komponen saluran lain yang mempunyai sifat airtanah karst baik agresiv maupun tidak agresiv yang bila bercampur akan menghasilkan air agresiv terhadap batuan karbonat di wilayah ini.

Selanjutnya, sifat agresivitas ini dianalisis pula dengan menggunakan pendekatan nilai indeks kejenuhan (Saturation Indices=SI) terhadap mineral kalsit yang diperoleh dengan bantuan perangkat lunak NETPATH 2.1.3 (Plummer et.al, 1991). Hasil perhitungan disajikan pada Tabel 5.

Tabel 5. Nilai Indeks Kejenuhan Terhadap Mineral Kalsit

\begin{tabular}{|r|l|c|r|}
\hline No & \multicolumn{1}{|c|}{ Sampel } & Koordinat & Indeks Kejenuhan \\
\hline 1 & Inlet S. Pentung & $472152 ; 9122480$ & -1.32 \\
\hline 2 & G. Jomblangan & $472212 ; 9122178$ & -0.69 \\
\hline 3 & G. Rinjani & $472563 ; 9119769$ & -0.80 \\
\hline 4 & G. Gilap & $472890 ; 9119224$ & -0.35 \\
\hline 5 & G. Jomblang & $473289 ; 9116815$ & -0.32 \\
\hline 6 & L. Jurangjero & $466886 ; 9111126$ & -0.12 \\
\hline 7 & G. Bribin & $464695 ; 9111695$ & -0.09 \\
\hline 8 & G. Sodong & $467983 ; 9109165$ & -0.43 \\
\hline
\end{tabular}

Dari Tabel 5 terlihat bahwa nilai SI pada semua sampel menunjukkan nilai dengan kondisi tidak jenuh (undersaturated) terhadap mineral kalsit. Hanya saja jika dilihat sebaran dan pola nilai SI dari hulu ke hilir mempunyai kecenderungan mendekati kondisi setimbang $(\mathrm{SI}=0)$ kearah hilir seperti yang ditemui di G. Bribin dan L. Jurangjero (Gambar 6). Pada sistem bocoran upstream G. Bribin ke G. Sodong, nilai SI yang terukur di G. Sodong menunjukkan nilai $-0,43$ dan masih jauh dari nilai setimbang, dan variasi nilai SI dari sistem Bribin-Sodong ini ditunjukkan pada Gambar 7. 


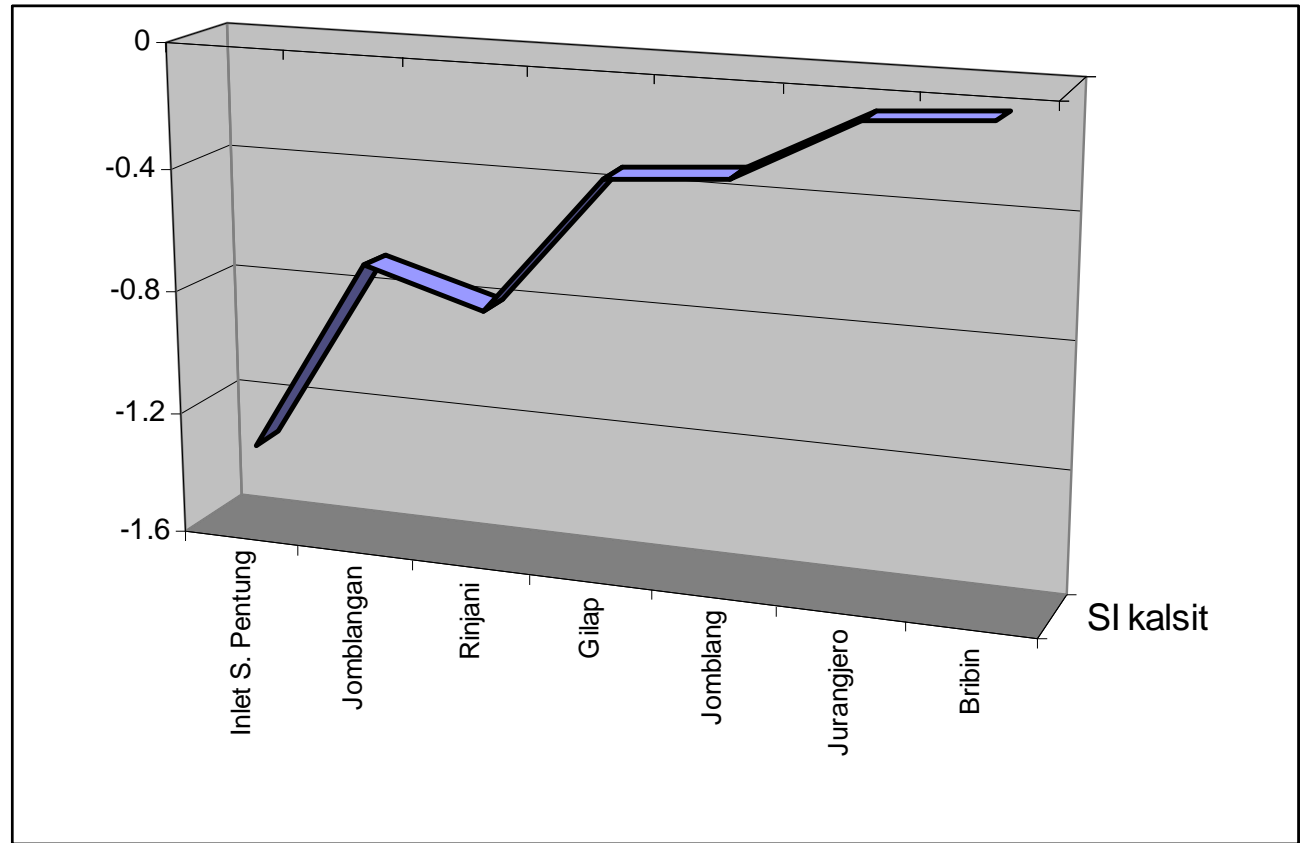

Gambar 6. Variasi Nilai Indeks Kejenuhan Dari Hulu Ke Hilir Sungai Bribin

Seperti halnya pada pengeplotan dengan grafik hubungan pada sistem $\mathrm{pH}$-suhu-CaCO3 dan metode untuk menghitung $\triangle \mathrm{pH}$ dan $\triangle \mathrm{TAC}$, maka nilai indeks kejenuhan terhadap mineral kalsit dari Goa Bribin ke Goa Sodong mengalami kenaikan indeks agresivitas yangberarti airtanah karst semakin mudah melarutkan batuan karbonat atau dengan kata lain kebocoran masih mungkin terjadi pada masa-masa mendatang atas dasar nilai SI dan agresivitas airtanah karst untuk melarutkan batuan karbonat.

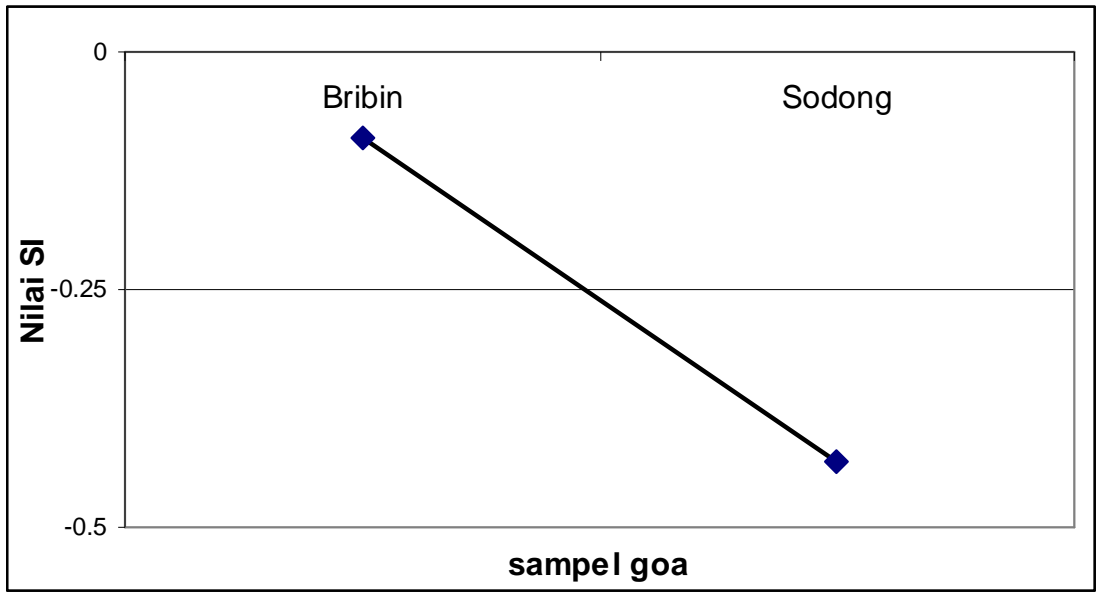

Gambar 7. Variasi Nilai Indeks Kejenuhan Sistem Bocoran Bribin-Sodong

Selanjutnya, Gambar 8 menunjukkan secara keseluruhan sifat agresivitas airtanah karst pada daerah tangkapan Sungai Bribin. Atas dasar satu kali pengambilan sampel, terlihat bahwa terdapat beberapa penggal/bagian dari Sungai Bribin yang mempunyai tingkat agresivitas untuk melarutkan batuan karbonat. Pada bagian hulu, terutama pada ponor inlet Sungai Pentung, airtanah bersifat agresiv dengan nilai indeks kejenuhan (SI) adalah $-1,32$ yang berarti air masih mampu untuk melarutkan mineral kalsit untuk membentuk lorong-lorong solusional. Agresivitas airtanah karst yang cukup potensial (agak agresiv) 
ini juga ditemui pada L. Jomblangan dengan nilai $S I=-0,69$ dan juga di G. Rinjani dengan nilai $S I=-0,8$. Sedikit ke arah hilir, sifat agak sedikit agresiv ditemui di G. Gilap dan G Jomblang dengan nilai SI berturutturut adalah $-0,35$ dan $-0,32$ ). Ke arah hilir, nilai agresivitas yang mendekati setimbang dijumpai di $L$. Jurangjero dan G. Bribin yang merupakan hilir/outlet dari S. Bribin dengan nilai SI berturut-turut adalah 0,12 dan $-0,09$. Interpretasi dari nilai ini adalah airtanah karst pada 2 sampel ini sudah jenuh terhadap mineral kalsit dan cenderut untuk tidak melarutkan mineral kalsit dan sedikit lagi akan mencapai fase supersaturated (mengendapkan/mengkristalkan) mineral kalsit dan membentuk padatan.

Selanjutnya, anomali ditemukan pada sistem bocoran Bribin-Sodong dimana nilai agresivitas di G. Sodong adalah agak agresiv dengan nilai $\mathrm{SI}=-0,43$ yang berarti masih mampu melarutkan batuan gamping dengan sifat mamsih mampu untuk membentuk/memperbesar saluran. Hal inilah yang perlu dikaji, karena jika pembentukan saluran ini terus berlangsung, maka kebocoran debit S. Bribin juga akan terus bertambah dari waktu ke waktu.

\section{KESIMPULAN}

Secara umum, terdapat tiga kalsifikasi sifat agresivitas aiartanah karst di Sungai Bribin yaitu : (i)di daerah hulu dengan sifat agresiv yang ditemui pada inlet S. Pentung; (ii)daerah tengah dengan sifat agak agresiv yang diwakili oleh L. Jomblangan dan G. Rinjani; dan (iii) daerah hilir yang sudah mendekati kondisi setimbang yang diwakili oleh L. Jurangjero dan G. Bribin. Selain itu anomali ditemui pada sistem bocoran ke G. Sodong dengan sifat agak agresiv dan mengindikasikan kebocoran debit $\mathrm{S}$. Bribin yang akan bertambah dari waktu ke waktu.

\section{DAFTAR PUSTAKA}

Adji T.N. dan Emilya N., Optimasi Airtanah karst Sebagai Pemasok Air Domestik Pada Kawasan Kritis Air di Gunung Kidul, Laporan Penelitian, Fakultas Geografi UGM

Adji, T.N. dan Haryono, E., 1999. Konflik Antara Pemanfaatan Batugamping dan Konservasi Sumberdaya Air Das Bribin di Wilayah Karst Gunung Sewu, Makalah Lokakarya Nasional Menuju Pengelolaan Sumberdaya Wilayah Berbasis Ekosistem Untuk Mereduksi Konflik Antar Daerah, Yogjakarta, , Fakultas Geografi, Universitas Gadjah Mada, September 1999

Adji, T.N., 1997. Kualitas Air Goa-Goa Karst di Sekitas Cekungan Wonosari, Studi Kasus: DAS Bawah Tanah Bribin, Kabupaten Gunung Kidul, DIY. Skripsi Sarjana, Fakultas Geografi UGM

Adji, T.N., Haryono, E., Woro, S, 1999, Kawasan Karst dan Prospek Pengembangannya di Indonesia, Seminar PIT IGI di Universitas Indonesia, 26-27 Oktober 1999

Appelo. C.A.J. and Postma, D., 1994. Geochemistry, groundwater and pollution. A.A. Balkema, Rotterdam, 536p.

Bogli, 1980. Karst Hydrology and Physical Speleology. Springler-Verlag

Fakultas Kehutanan, 1993.. Penyusunan Arahan Konservasi Tanah dan Air di Daerah Tangkapan Air Gua Bribin Kabupaten Gunung Kidul DIY. Kerjasama antara Dinas Kehutanan DIY - Fakultas Kehutanan UGM Yogyakarta

Ford, D. and Williams, P. 1992. Karst Geomorphology and Hydrology, Chapman and Hall, London

Gillieson, D., 1996, Caves: Processes, Development, and Management, Blackwell, Oxford

Haryono, E. dan Adji, T.N. 2004. Geomorfologi dan Hidrologi Karst. Yogyakarta: Kelompok Studi Karst, Fakultas Geografi, Universitas Gadjah Mada

Jankowski, J., 2002. Groundwater Environment, Short Course Note, School of Geology, University Of New South Wales, Sydney, Australia

McDonald and Partners,1984. Greater Yogyakarta-Groundwater Resources Study. Vol 1: Main Report. Yogyakarta: Directorate General of Water Resources Development Project (P2AT) 
Plummer,L.N., Prestemon,E.C. and Parkhurst, D.L., 1991. An Interactive Code (NETPATH) for modelling NET geochemical reactions along a flowPATH. U.S. Geological Survey, Water Resources Investigation. Rep. 914078, pp 130., http://h2o.usgs.gov/software/

Setyahadi, A., 2002. Koefisien Limpasan Permukaan Kawasan Karst Gunung Sewu (Studi Kasus Daerah Tangkapan Air Sungai Bawah Tanah Bribin, Kabupaten Gunung Kidul, DIY). Skripsi Sarjana, Fakultas Geografi UGM

Sinar Harapan, 2004. Mesin Bor Pembangunan Bendung Gua Bribin Tiba. 18 Juni 2004. www.sinarharapan.co.id/berita/0406/17/nus04.html

Suara Merdeka, 2004. Warga Gunungkidul Bakal Nikmati Air Bersih. 21 Juni 2004. http://www.suaramerdeka.com/harian/0406/21/ked08.htm 


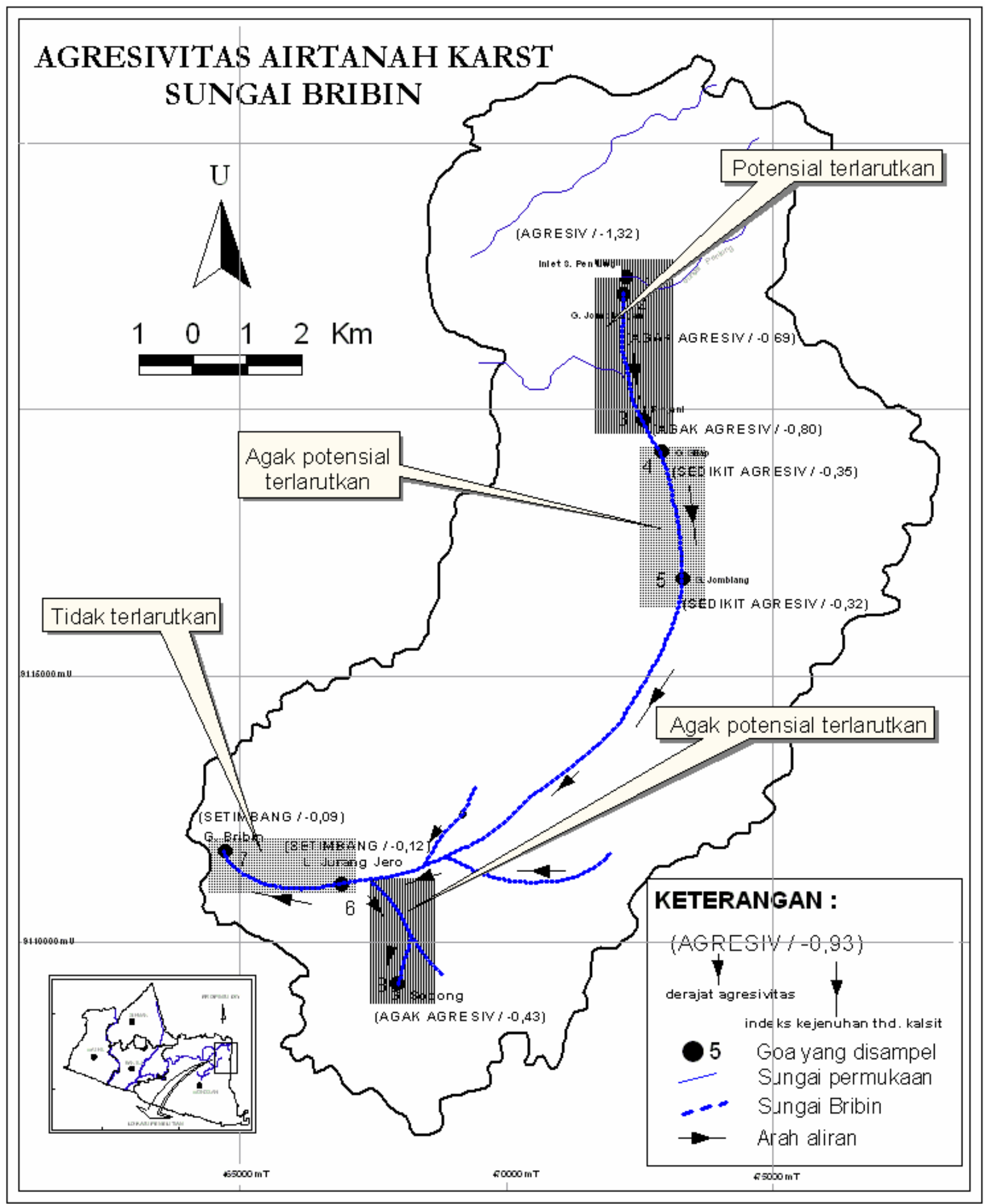

Gambar 8. Sebaran Agresivitas Airtanah karst Sungai Bribin 